AL. 2. 2002- 226

2

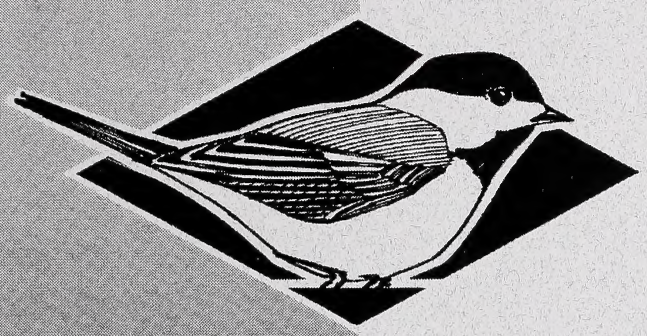

An Evaluation of the

Fish \& Whidilie Division

Ferruginous Hawk Population in Alberta Based on Recent Trend Data

RESOURCE STATUS AND

ASSESSMENT BRANOH

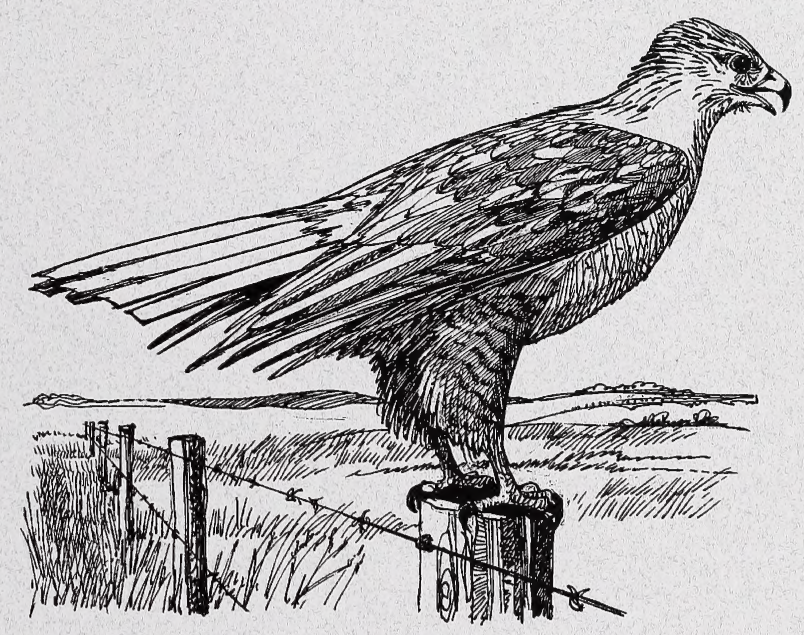

Alberta Species at Risk Report No. 52 
Digitized by the Internet Archive in 2016 


\title{
An Evaluation of the Ferruginous Hawk Population in Alberta Based on Recent Trend Data
}

\author{
David P. Stepnisky \\ Gary L. Erickson \\ Jamie Iwaasa \\ and \\ Brad Taylor
}

Alberta Species at Risk Report No. 52

March 2002

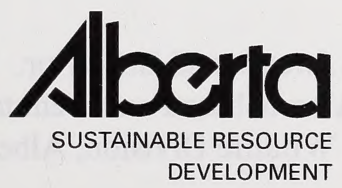


Publication No.: I/075

ISBN: 0-7785-2188-5 (Printed Edition)

ISBN: 0-7785-2189-3 (On-line Edition)

ISSN: 1496-7219 (Printed Edition)

ISSN: 1496-7146 (On-line)

Illustration: Brian Huffman

For copies of this report, contact:

Information Centre - Publications

Alberta Environment / Alberta Sustainable Resource Development

Main Floor, Great West Life Building

9920 - 108 Street

Edmonton, Alberta, Canada T5K 2M4

Telephone: (780) 422-2079

OR

Information Service

Alberta Environment / Alberta Sustainable Resource Development \#100, 3115 - 12 Street NE

Calgary, Alberta, Canada T2E 7J2

Telephone: (403) 297-3362

OR

Visit our web site at:

http://www3.gov.ab.ca/srd/fw/riskspecies/

This publication may be cited as:

Stepnisky, D.P., G.L. Erickson, J. Iwaasa and B. Taylor. 2002. An evaluation of the ferruginous hawk population in Alberta based on recent trend data. Alberta Sustainable Resource Development, Fish and Wildlife Division, Alberta Species at Risk Report No. 52. Edmonton, AB. 16pp. 


\section{TABLE OF CONTENTS}

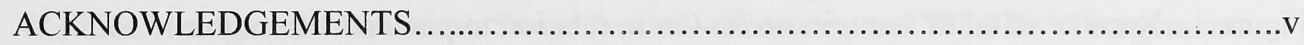

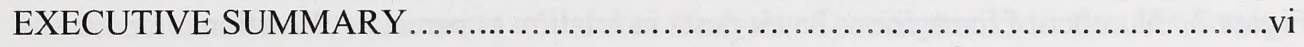

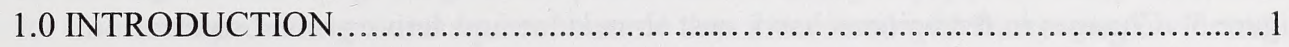

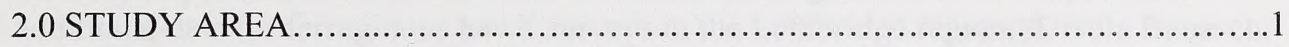

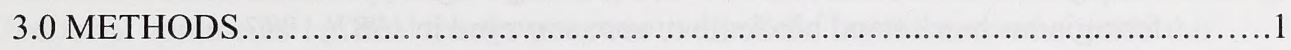

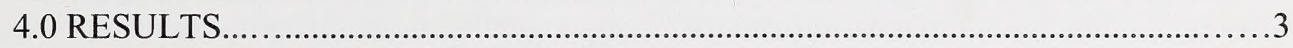

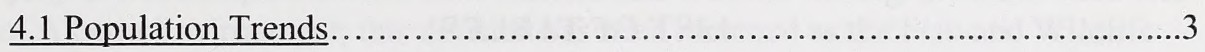

4.2 Factors Potentially Responsible for Population Size in $2000 \ldots \ldots \ldots \ldots \ldots \ldots . . . . . . .4$

4.2.1 Ecoregions..............................................

4.2.2 Cultivation.....................................................

4.2.3 Oil and Gas Activity..........................................

4.2.4 Ground Squirrels............................................

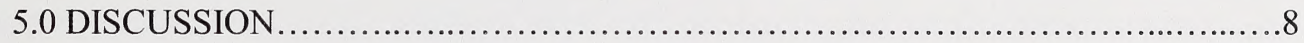

6.0 MANAGEMENT IMPLICATIONS AND FUTURE DIRECTIONS ................12

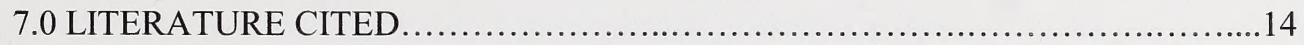




\section{LIST OF FIGURES}

Figure 1. Number of adult ferruginous hawks in relation to percent cultivation........5

Figure 2. Number of ferruginous hawk nests in relation to percent cultivation.........5

Figure 3. Changes in ferruginous hawk nest abundance and active ground squirrel

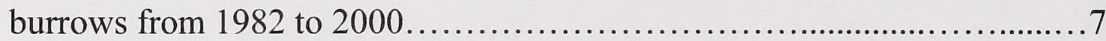

Figure 4. Ferruginous hawk abundance in the Lethbridge region, based on 25 ferruginous hawk trend blocks that were surveyed in 1982, 1987, $1992,1997,1999,2000$, and 2001 8

\section{LIST OF TABLES}

Table 1. The estimated number of pairs of ferruginous hawks in southeastern Alberta, 1982-2000. 3

Table 2. Number of ferruginous hawk nests and adults located in each plot by ecoregion. 4

Table 3. Well site presence in relation to ferruginous hawk abundance 6

Table 4. Results of ground squirrel surveys conducted in the study region. .7 


\section{ACKNOWLEDGEMENTS}

We thank Josef Schmutz (University of Saskatchewan), Gordon Court (Fisheries and Wildlife Management Division), Steve Brechtel (Fisheries and Wildlife Management Division), and Ursula Banasch (Canadian Wildlife Service) for their encouraging words and recommendations at the onset of the data analysis. Special thanks to Tim Schowalter for sharing his knowledge on ground squirrels and to Darcy Shyry (University of Alberta) for information on the ground squirrel burrow data associated with burrowing owl trend block surveys. Leo Dube (Fisheries and Wildlife Management Division) provided additional data for ferruginous hawk surveys in the Lethbridge region. Ursula Banasch, Gordon Court, Sam Barry, Josef Schmutz, Sue Cotterill, and Robin Gutsell provided editorial comments. A final thanks goes out to all of the landowners who made this survey possible.

This project was completed when the Fisheries and Wildlife Management Division was part of Alberta Environment; this division has been renamed as the Fish and Wildlife Division and is now part of Alberta Sustainable Resource Development. 


\section{EXECUTIVE SUMMARY}

In 1982, a ferruginous hawk monitoring survey was established in southeastern Alberta; it was repeated in 1987, 1992 and 2000. The ferruginous hawk is a threatened species under the Alberta Wildlife Act, making it important to monitor any changes that may be occurring in the population. Data from the 2000 survey were analysed to estimate population size, document habitat changes that have occurred over time, and test for factors that may have contributed to changes in the population. The provincial population size in 2000 was estimated to be 731 pairs, which is considerably less than the estimate of 1702 pairs in 1992. This decline in the population of ferruginous hawks appears related to a decline in the abundance of Richardson's ground squirrels; however, it is difficult to draw firm conclusions because of inaccuracies and bias in ground squirrel surveys. As with previous surveys, ferruginous hawks nested in areas with lower levels of cultivation. Presence of oil and gas well sites appeared to have no effect on the abundance of ferruginous hawk adults or nests. In order to ensure the long-term persistence of ferruginous hawk populations in southeastern Alberta, it is critical to gain a better understanding of ground squirrel populations, the main prey species of the ferruginous hawk in Alberta. The continued presence of the squirrel on the landscape will be critical for the survival of the ferruginous hawk. We recommend that managers establish a more effective and regular ground squirrel monitoring program as well as continuing ferruginous hawk surveys. In addition, ferruginous hawk surveys should be conducted annually, in order to document any annual variability that is missed in the 5-year surveys. Whenever possible, private landowners and industry should be encouraged to maintain rangeland rather than converting the land base to cultivated fields. Educational material could be useful in accomplishing this goal. 


\subsection{INTRODUCTION}

With growing concern over the integrity of the prairie landscape, it is important to monitor all species that rely on prairie habitats. The ferruginous hawk (Buteo regalis) is a species dependent on grasslands and is an important species to monitor in the prairies of Alberta. As with all birds of prey, the success of ferruginous hawk populations is dependent on an adequate prey base; changes in hawk populations can reflect changes occurring lower down the food chain. The importance of monitoring ferruginous hawk populations is recognized by its status as a Species of Special Concern (COSEWIC 2001) in Canada, and as a threatened species in Alberta (Province of Alberta 1999).

In 1982, a long-term monitoring project was initiated to estimate ferruginous hawk abundance in Alberta and to monitor changes in density and distribution through time (Schmutz 1982). This survey was repeated in 1987 and 1992 in order to: 1) give an estimate of population size; 2) document population trend over time; and 3) look at land use in relation to ferruginous hawk populations (Schmutz 1993). The survey was repeated most recently in 2000, with the same three objectives in mind. The results of the 2000 survey are summarized in this report.

\subsection{STUDY AREA}

The data used in this report were collected as part of a long-term monitoring project for ferruginous hawks, established in 1982 (Schmutz 1982), and repeated in 1987, 1992, and 2000 (Schmutz 1987a, Schmutz 1993, Taylor and Iwaasa 2000a). The study area encompasses a large part of southeastern Alberta, from Consort in the north, west to Calgary, south to the Montana border, and east to the Saskatchewan border. The total study area is approximately $77,947 \mathrm{~km}^{2}$ in size; however, because it was not feasible to survey the entire area, a total of 85 plots (each $41.4 \mathrm{~km}^{2}$, or 16 sections, in size and randomly distributed across the landscape) were searched. These plots amount to a sub-sample of $3519 \mathrm{~km}^{2}$, accounting for $4.5 \%$ of the total study area.

Three major ecoregions are represented in the study area: the Dry Mixed-Grass, Mixed-Grass, and Fescue-Grass (Strong and Leggat 1992). A fourth ecoregion (the Aspen Parkland) is also encountered in the northern portion of the study area, but only makes up a small portion of land used by the ferruginous hawk in comparison to the other ecoregions. The landscape in the study area is dominated by agriculture, with a patchwork of cultivated lands and pasturelands, with a few remnant areas of native prairie. Oil and gas exploration, various livestock industries, and urban settlements are a few of the other dominant land-use features present.

\subsection{METHODS}

In 1982, Schmutz established 80 survey plots based on randomly selected points across the study area (Schmutz 1982). A total of 85 plots were resurveyed in 2000, based on the original plots selected in 1982, as well as several additional plots that were added to the survey in 1987 (Schmutz 1987a). One plot was omitted because of a lack of landowner permission and limited road access. Taylor and Iwaasa (2000a) provide a complete list of all plots surveyed in 2000. In 2000, 17 additional plots were established in the Foothills Fescue region (Taylor and Iwaasa 
2000b). These 17 plots were not included in this analysis because the data were not comparable with previous surveys. All plots in the survey are $6.8 \mathrm{~km} \mathrm{X} 6.8 \mathrm{~km}$ ( 4 miles X 4 miles) in size, an area of $41.4 \mathrm{~km}^{2}\left(16\right.$ miles $\left.^{2}\right)$.

Surveys were conducted between May 29 and July 6. Maps showing known hawk nests were not used in order to avoid a bias in the survey. Field surveys were conducted using the same methodology as described in previous ferruginous hawk surveys (Schmutz 1982, 1987a, 1993). The use of ATV's rather than trail bikes had some limitations, as use was often restricted to designated truck trails. Land use and ferruginous hawk sightings were mapped in each plot by driving the area with a truck and recording features (such as trees, roads, oil/gas well-sites, and homesteads) on the landscape. Every effort was made to record ferruginous hawk nest activity, by walking or using ATV's to approach individual trees or groups of trees within the plot. Spotting scopes were also used where observations from a distance were more effective, as some nests were inaccessible (Taylor and Iwaasa 2000a). An active nest was one in which a single bird was present on a stick nest, a pair of birds were perched in a tree close to a stick nests, or where white-wash or droppings were found below a stick nest. An unused nest was a stick nest that had no signs of recent use (lack of white-wash, droppings, feathers, or fresh nesting material). All nest observations were made from a vantage point that allowed a visual inspection from above. No trees or platforms were climbed to look directly into the nest. Presence of redtailed (Buteo jamaicensis) and Swainson hawks (Buteo swainsoni) was also recorded; these data are not included in this report.

The percent cultivation and the percent tame and native pasture were delineated on 1:250,000 base maps. During previous surveys, the relative abundance of Richardson's ground squirrels (Spermophilus richardsonii) was assessed using line transect surveys which were placed selectively on the landscapes in areas thought to have ground squirrels. This was discontinued in 2000 because of concerns over inaccuracy of methodology resulting from surveyor bias and bias in the placement of transects. Alberta Fisheries and Wildlife Management Division conducted burrowing owl surveys from 1994 to 2000 in portions of the ferruginous hawk survey study area around Hanna (H-blocks) and Kininvie (K-blocks). However, the survey occurred in different plots than the ferruginous hawk surveys. With permission from Alberta Fisheries and Wildlife Management Division, the 1994-2000 data were used to determine trends in abundance of ground squirrels for that time period. Although not directly comparable to the ground squirrel data from ferruginous hawk surveys, the burrowing owl survey data were useful in looking at squirrel trends during the past several years.

Ground squirrel data were collected for the burrowing owl trend blocks by driving an $800 \mathrm{~m}$ transect and recording all active ground squirrel burrows. Active ground squirrel burrows were those that appeared to be used recently by squirrels (with scats, scratch marks, or no cob-webs present). This methodology is similar to the previous ferruginous hawk ground squirrel surveys, where transects (varying from $500 \mathrm{~m}$ to $1500 \mathrm{~m}$ in length) were traveled and all active ground squirrel burrows were recorded (Schmutz and Hungle 1989). To compare active ground squirrel burrow abundance, the numbers were averaged for all of the plots surveyed and then divided by the total number of kilometers surveyed in order to estimate the number of active ground squirrel burrows per kilometer in a given survey year. 
Other data and information sources were investigated in an attempt to obtain additional population trend information for ground squirrels, including personal observations of ground squirrel numbers (obtained from various field staff in Agriculture and Fisheries and Wildlife Management) and attempts at relating the amount of poison used to control populations (Schmutz and Hungle 1989). However, these personal accounts and poison data proved insufficient because of an inability to quantify personal accounts and a lapse in availability of effective poisons for use by landowners.

For the ferruginous hawk trend data, population size and $95 \%$ confidence intervals were estimated using the same calculations as Schmutz (1982). When testing the effects of various factors on ferruginous hawk nest and adult presence, non-parametric statistics were used because the data were highly variable, with many zero values, and could not be corrected through transformation.

\subsection{RESULTS}

\subsection{Population Trends}

In 2000, the number of pairs of ferruginous hawks in Alberta was estimated to be 731 (Table 1). This is less than half the number of ferruginous hawks that were estimated for the province in the 1992 survey (1702 pairs).

Ferruginous hawk nest abundance decreased on 29 plots, increased on 7 plots, and remained the same on 49 plots. The number of plots that showed decreases in nest abundance, in comparison to the number of plots that showed an increase (29:7), was significantly different than the ratio of 50:50 that would be expected if no change occurred in the population (Binomial Test, $P=0.001$ ). This significant difference points to a real decrease in the population of ferruginous hawks in Alberta from 1992 to 2000.

Although overall population estimates were down in 2000, increases in numbers were recorded in certain plots within the study area. Increases in numbers of nests were recorded in most plots in the Milk River Region, and several plots in the Brooks region (totaling 7 plots).

Table 1. The estimated number of pairs of ferruginous hawks in southeastern Alberta, 1982-2000

\begin{tabular}{ccccccc}
\hline Year & $\begin{array}{c}\text { Number of } \\
\text { Plots }\end{array}$ & $\begin{array}{c}\text { Study Area } \\
\left.\mathbf{( k m}^{2}\right)^{\mathbf{b}}\end{array}$ & $\begin{array}{c}\text { Nests/ } \\
\text { Plot }\end{array}$ & Range & $\begin{array}{c}\text { Estimated } \\
\text { Number of } \\
\text { Pairs }\end{array}$ & $\begin{array}{c}\mathbf{9 5 \%} \\
\text { Confidence } \\
\text { Interval }\end{array}$ \\
\hline $\mathbf{1 9 8 2}$ & 80 & 74,686 & 0.587 & $0-7$ & 1059 & $630-1488$ \\
$\mathbf{1 9 8 7}$ & 83 & 77,947 & 0.94 & $0-6$ & 1770 & $1265-2275$ \\
$\mathbf{1 9 9 2}$ & 83 & 77,947 & 0.904 & $0-7$ & 1702 & $1181-2223$ \\
$\mathbf{2 0 0 0}$ & 85 & 77,947 & 0.388 & $0-6$ & 731 & $365-1097$ \\
\hline
\end{tabular}

${ }^{a}$ 1982-92 data from Schmutz 1993

${ }^{\mathrm{b}}$ An additional $3261 \mathrm{~km}^{2}$ was added to the northwest portion of the survey area in 1987 
On today's prairie landscape, there are countless factors that can affect populations of ferruginous hawks. Cultivation of agricultural lands, industrial activity (such as oil and gas), increasing urban settlement, and climate change are a few of the factors. Without a proper cumulative impacts assessment, it is difficult to tell if and how all of these factors are affecting the ferruginous hawk; however, through analysis of the 2000 population data in relation to some of these individual footprints on the landscape, some insights can be gained into factors that may have contributed most to this hawk's decline.

\subsubsection{Ecoregions}

The ferruginous hawk surveys were conducted in an area that encompassed four major ecoregions of Alberta (Strong and Leggat 1992). On average, more nests were found in plots in the Dry Mixed Grass ecoregion and more adults were found in plots in the Fescue Grass ecoregion, compared to the other ecoregions (Table 2). However, these differences were not significant for both adults (Kruskal Wallis, $P=0.230$ ) and for nests (Kruskal Wallis, $P=0.359$ ). These statistics should be viewed with caution, as the high degree of variability within ecoregions makes results difficult to interpret.

Table 2. Number of ferruginous hawk nests and adults located in each plot, by ecoregion.

\begin{tabular}{lccc}
\hline Ecoregion* & $\begin{array}{c}\text { Number of Plots } \\
\text { Located in } \\
\text { Ecoregion }\end{array}$ & $\begin{array}{c}\text { Mean Number of } \\
\text { Nests per Plot } \\
\text { (standard deviation) }\end{array}$ & $\begin{array}{c}\text { Mean Number of Adults } \\
\text { per Plot (standard } \\
\text { deviation) }\end{array}$ \\
\hline Dry Mixed Grass & 50 & $0.50(+/-1.11)$ & $0.88(+/-1.73)$ \\
Mixed Grass & 24 & $0.17(+/-0.48)$ & $0.29(+/-0.91)$ \\
Fescue Grass & 9 & $0.44(+/-0.73)$ & $1.00(+/-1.80)$ \\
Aspen Parkland & 2 & $0.00(+/-0.00)$ & $0.50(+/-0.71)$ \\
\hline
\end{tabular}

* From Strong and Leggat 1992

\subsubsection{Cultivation}

For purposes of analysis, plots were separated into 5 levels of cultivation; those with 0-20 percent cultivation, those with 21-40, those with 41-60, those with 61-80, and those with 81-100. By plotting the mean number of ferruginous hawk nests and adults observed per plot by the level of cultivation, a relationship between the percent cultivation and the mean number of ferruginous hawks and nests can be seen (Figures 1 and 2). With greater levels of cultivation, fewer ferruginous hawks and their nests were observed (nests: Spearman's $\mathrm{r}_{\mathrm{s}}=-0.185, P=0.09$; adults: $\mathrm{r}_{\mathrm{s}}=-0.352, P=0.001$ ). To further test the significance of this relationship, the numbers of nests and adults were plotted against the percent cultivation and a linear regression analysis was performed. The result was a significant relationship for both nests $(P=0.009)$ and for adults $(P=0.002)$; however, these results had very low $\mathrm{r}$-squared values $(0.067$ for nests and 0.092 for adults) as the large number of zero values throughout the study area made it difficult to deliver meaningful results. 


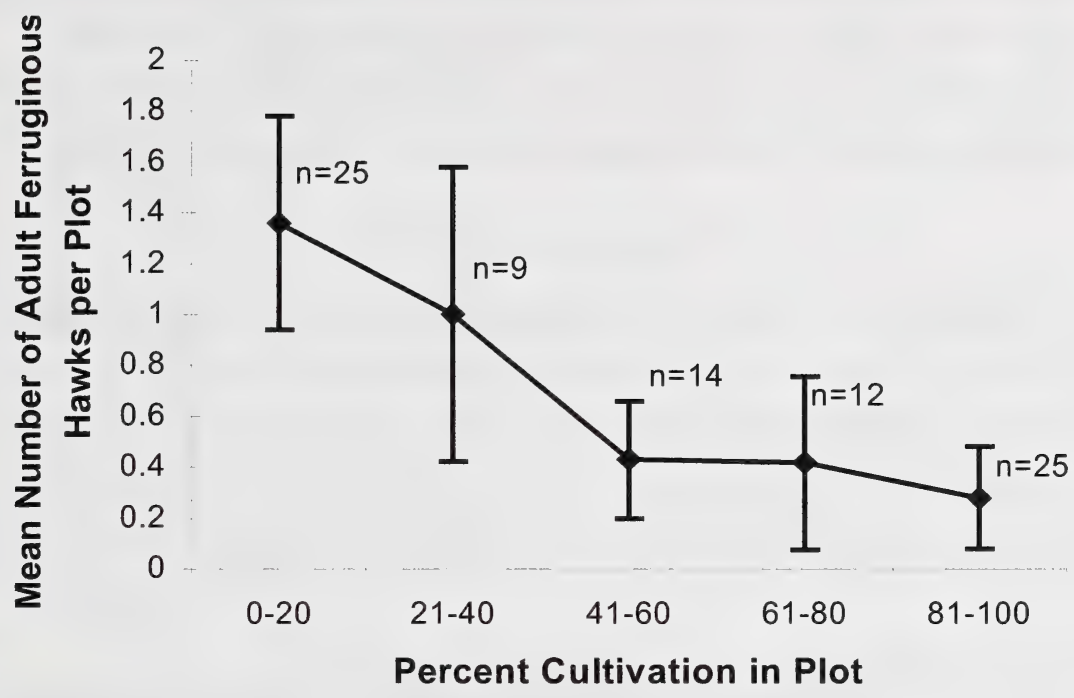

Figure 1. Number of adult ferruginous hawks in relation to percent cultivation. The bars represent standard error.

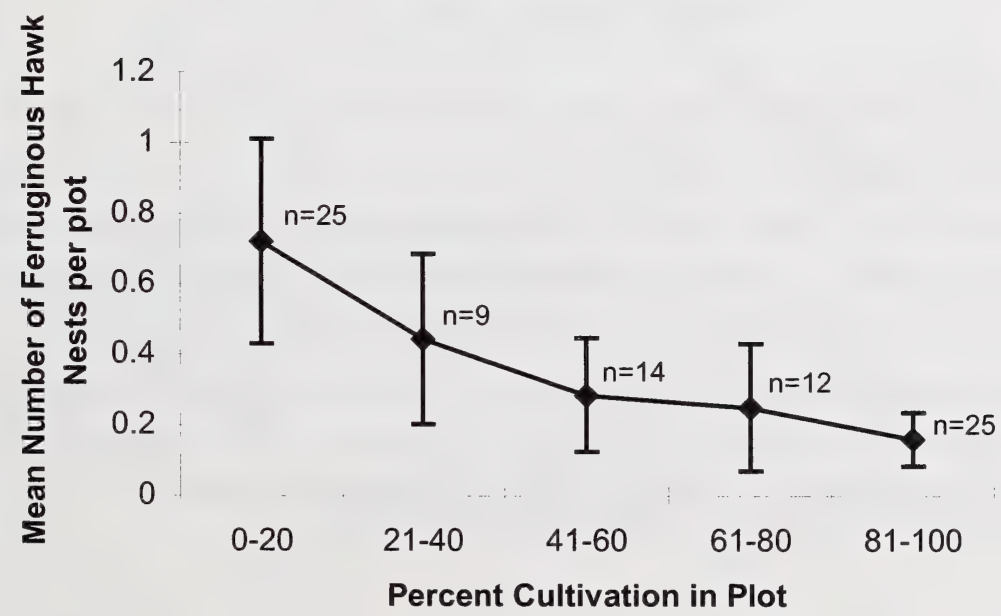

Figure 2. Number of ferruginous hawk nests in relation to percent cultivation. The bars represent standard error. 
To determine whether cultivation might be a contributing factor in the decline of the ferruginous hawk in 2000, levels of cultivation were compared between the last survey (1992) and this survey. In 1992, the average percent of each plot under cultivation was 50.74, which was almost identical to the area under cultivation in 2000 (49.91\%). Looking even further back in time, levels of cultivation were estimated at 49\% in 1982 and at 54\% in 1987 (Schmutz 1993).

\subsubsection{Oil and Gas Activity}

Taylor and Iwaasa (2000a) noted a considerable number of new oil and gas wells in 2000. In order to test the effect that oil and gas presence may have on ferruginous hawk nest and adult presence, all plots with at least one well-site were compared to plots without oil and gas well sites (Table 3). Although the average number of nests and adults was greater for areas with well sites, no significant difference showed in numbers between plots with well-sites compared to those without for both nests (Mann-Whitney-U, $P=0.827$ ) and adults (Mann-Whitney-U, $P=$ 0.986).

Table 3. Well site presence in relation to ferruginous hawk abundance.

\begin{tabular}{ccc}
$\begin{array}{c}\text { Number of } \\
\text { Plots }\end{array}$ & $\begin{array}{c}\text { Mean Number of } \\
\text { Ferruginous Hawk } \\
\text { Nests/Plot (standard } \\
\text { deviation) }\end{array}$ & $\begin{array}{c}\text { Mean Number of } \\
\text { Ferruginous Hawk } \\
\text { Adults/Plot (standard } \\
\text { deviation) }\end{array}$ \\
\hline & $0.62(+/-0.62)$ & $1.04(+/-2.2)$
\end{tabular}

$\begin{array}{lllc}\text { Well-site(s) Present } & 26 & 0.62(+/-0.62) & 1.04(+/-2.2) \\ \text { Well-site(s) Absent } & 59 & 0.29(+/-0.56) & 0.58(+/-1.13)\end{array}$

\subsubsection{Ground Squirrels}

The average number of active ground squirrel burrows $/ \mathrm{km}$ recorded in 2000 was 5.7 (from the burrowing owl K-block surveys) and 2.1 (from the burrowing owl H-block surveys) active burrows $/ \mathrm{km}$. This was fewer ground squirrels than observed in past ferruginous hawk surveys (Table 4). When related to the average number of ferruginous hawk nests recorded per plot in each survey year, ground squirrel abundance and ferruginous hawk nest abundance appear to be related. When populations of ground squirrels increased, the number of ferruginous hawk nests increased, and when ground squirrels declined, the number of ferruginous hawk nests declined (Figure 3). A statistical analysis could not be performed to test this relationship, as surveys for ground squirrels in 2000 were conducted on different plots within the study area than were hawk surveys. Looking at the ground squirrel data from the burrowing owl surveys, there appears to be a great deal of annual variation in ground squirrel abundance (Table 4). 
Table 4. Results of ground squirrel surveys conducted in the study region.*

\begin{tabular}{|c|c|c|c|c|c|c|c|}
\hline Year & Study & $\begin{array}{l}\text { Number of } \\
\text { Plots } \\
\text { Included in } \\
\text { Survey }\end{array}$ & $\begin{array}{l}\text { Total Number of } \\
\text { Active Ground } \\
\text { Squirrel Burrows } \\
\text { Counted in Survey }\end{array}$ & $\begin{array}{l}\text { Total Distance } \\
\text { Walked in } \\
\text { Survey }(\mathbf{k m})\end{array}$ & $\begin{array}{c}\text { Average Number of } \\
\text { Active Burrows } \\
\text { Recorded/km }\end{array}$ & $\begin{array}{c}\text { Maximum } \\
\text { Number of } \\
\text { Active } \\
\text { Burrows } \\
\text { Recorded/km } \\
\text { /Plot } \\
\end{array}$ & $\begin{array}{c}\text { Minimum } \\
\text { Number of } \\
\text { Active } \\
\text { Burrows } \\
\text { Recorded/km } \\
\text { /Plot } \\
\end{array}$ \\
\hline 1982 & $\begin{array}{c}\text { Ferruginous } \\
\text { Hawk Surveys }\end{array}$ & 14 & 376 & 21.5 & 17.5 & 72 & 0 \\
\hline 1987 & & 41 & 954 & 48.1 & 19.8 & 79 & 0 \\
\hline 1992 & & 31 & 232 & 29 & 8 & 30 & 0 \\
\hline 1994 & $\begin{array}{c}\text { Burrowing Owl } \\
\text { K-Block Surveys }\end{array}$ & 18 & 26 & 16.8 & 1.5 & 5 & 0 \\
\hline 1995 & & 18 & 266 & 28 & 9.5 & 33.1 & 0.6 \\
\hline 1997 & & 10 & 524 & 16 & 32.8 & 51.25 & 15 \\
\hline 1998 & & 11 & 152 & 10.4 & 14.6 & 43.8 & 1.3 \\
\hline 1999 & & 9 & 186 & 14.4 & 12.9 & 59.4 & 0 \\
\hline 2000 & & 10 & 91 & 16 & 5.7 & 19.4 & 0 \\
\hline 1997 & $\begin{array}{c}\text { Burrowing Owl } \\
\text { H-Block Surveys }\end{array}$ & 44 & 99 & 68 & 1.5 & 8.75 & 0 \\
\hline 1998 & & 46 & 74 & 71.2 & 1 & 7.5 & 0 \\
\hline 2000 & & 11 & 30 & 14.4 & 2.1 & 9.4 & 0 \\
\hline
\end{tabular}

* 1982-1992 data from Alberta Fisheries and Wildlife Management Division ferruginous hawk survey data archives;

1994-2000 data from Alberta Fisheries and Wildlife Management Division burrowing owl survey data archives.

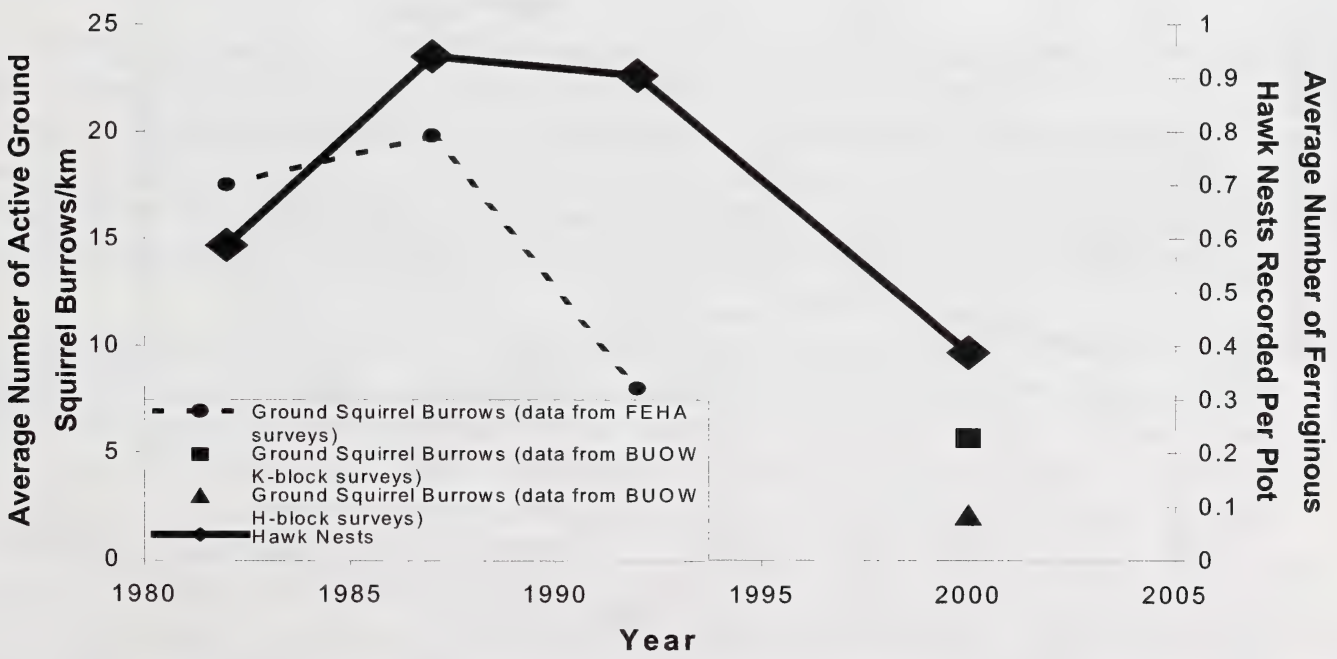

Figure 3. Changes in ferruginous hawk nest abundance and active ground squirrel burrows from 1982 to 2000 . 


\subsection{DISCUSSION}

A dramatic decline in the ferruginous hawk population was seen in the 2000 survey. Although this decline is cause for concern, it is important to note that a previous population low was observed in 1982, when the population was estimated at 1059 pairs (Table 1); there are several factors that may account for this result.

There are many concerns associated with five-year surveys for raptors. Natural events such as heavy storms or changes in prey numbers can result in a year of low breeding success. Without reporting annual numbers, five-year surveys run the risk of reporting poor/exceptional years for birds, rather than true population trends. Data have been collected consistently for 25 of the ferruginous trend blocks in the Lethbridge region for 1997, 1999, and 2001 (in addition to the regular five year surveys) and are shown in Table 4. Although the Lethbridge survey cannot be extrapolated across the entire ferruginous hawk range in Alberta, it does provide insight into the annual variability in numbers that exists for ferruginous hawks. By looking at data for ferruginous hawks in the Lethbridge region, it is clear that numbers of ferruginous hawk adults and nests can vary considerably, both between plots within a year, and between years.

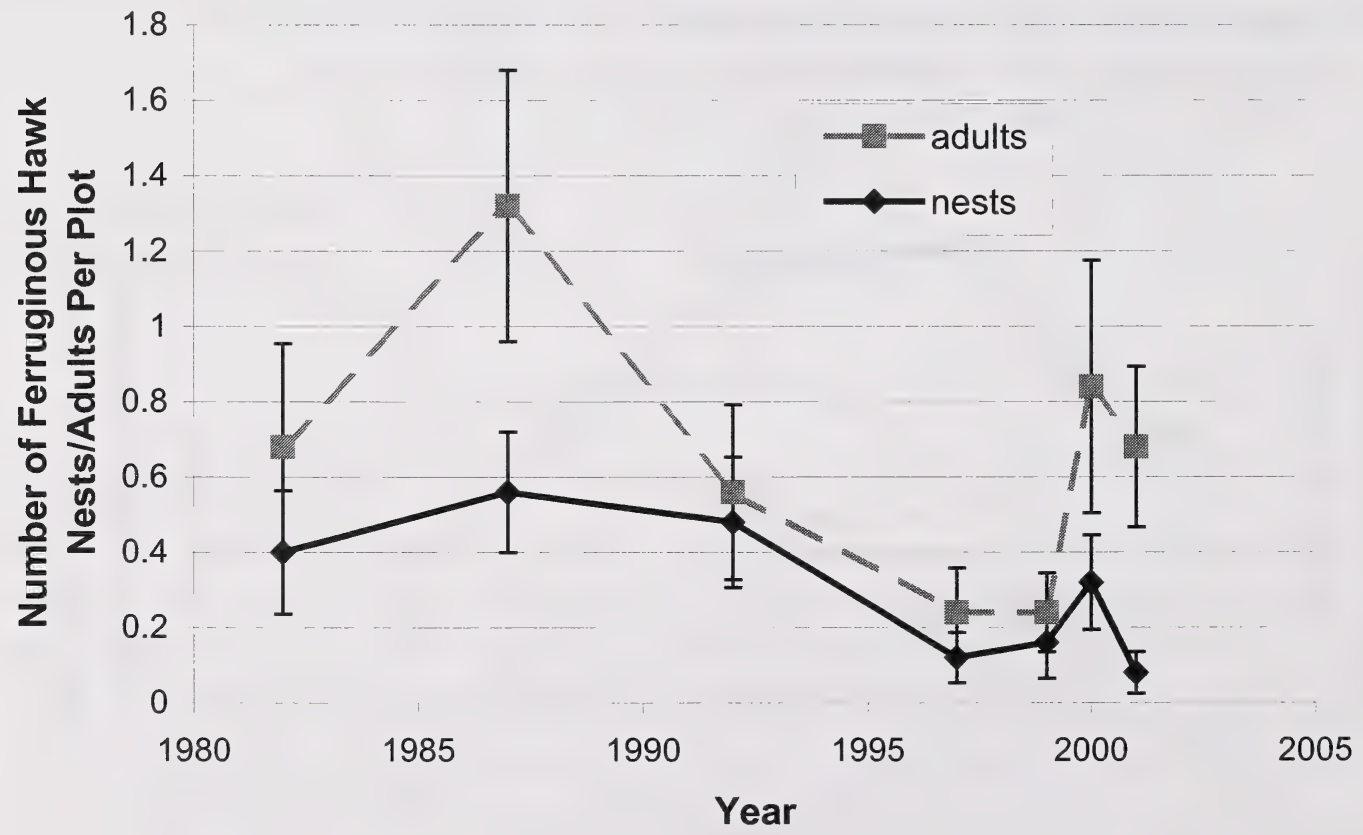

Figure 4. Ferruginous hawk abundance in the Lethbridge region, based on 25 ferruginous hawk trend blocks that were surveyed in 1982, 1987, 1992, 1997, 1999, 2000, and 2001. (data provided by Leo Dube, Lethbridge Fisheries and Wildlife Management Division). The bars represent standard error. 
The ferruginous hawk is a raptor of the "open country" found in grassland regions (Schmutz 1999). It is of no surprise that greater numbers of this hawk were found in plots located in the Dry Mixed Grass and Fescue ecoregions being the core of the grasslands in Alberta. Although fewer ferruginous hawks and nests were found in the Aspen Parkland and Fescue Grass ecoregions, the differences were not significant, suggesting that within the ferruginous hawk's range differences between ecoregions are not affecting abundance.

Contrary to what was expected, no significant difference was observed between the number of hawks in plots with oil and gas well-sites compared to those without. A slightly higher number of adults and nests was observed in plots with oil and gas development. This may be a direct result of a greater abundance of perching posts (such as well structures and buildings), or possibly an indirect result of the increased linear disturbance which could be attracting ground squirrel prey. Zelenak and Rotella (1997) found a higher abundance of ferruginous hawk nests in areas proximate to cropfields and roads. They hypothesized that this was a result of a greater abundance of ground squirrels along or near those edges. A similar effect could be seen through the creation of well-site roads where these areas are attracting hawks because of an increase in squirrel abundance. This theory is supported by recent work in southern Alberta that showed greater numbers of ground squirrels near or in roadside ditches when compared to other landscape features and undisturbed sites (Banasch pers. comm.). Reclamation of road-sides and well-sites may benefit ground squirrels, as certain tame grasses provide early season forage. The possible positive effects of oil and gas activity should be interpreted with caution, because such development also results in increased human activity and ferruginous hawks are reportedly wary of humans (Bechard and Schmutz 1995).

One thing not examined in the 2000 ferruginous hawk survey was nest abandonment that could result from oil and gas activity. White and Thurow (1985) showed that human activity around nest sites resulted in significantly fewer young being fledged from nests, and abandonment of nests. In Alberta, although no difference in nesting density was seen between plots with and without well sites, productivity was not measured. It has been suggested that ferruginous hawk productivity may be lower in areas adjacent to well-sites (Bechard and Schmutz 1995).

The data collected in the 2000 survey showed fewer ferruginous hawks and nests in areas with greater levels of cultivation. Similar results were recorded during previous Alberta surveys (Schmutz 1984, Schmutz 1987b) where nest abundance decreased steadily with increasing cultivation. The exception occurred during the 1987 and 1992 surveys, where the hawks were found to be most abundant in areas of moderate cultivation, nearly absent in areas of high cultivation, and low in areas with no cultivation (Schmutz 1989). The avoidance of cultivated areas by the ferruginous hawk is not unique to Alberta. Howard and Wolfe (1976) found 97 nests in Utah and Idaho, none of which were located in cultivated areas. They hypothesized that if intensive agriculture was practiced on the entire landscape, densities and reproductive success of these hawks would be greatly reduced by increased disturbance, loss of nesting sites, and reduction of major prey populations.

Gilmer and Stewart (1983) found ferruginous hawks to be nesting primarily in pasture and hay land, even though a large percentage of the study area was under cultivation in North Dakota. 
Few nests were located in areas with greater than $50 \%$ cultivation, and they concluded that grassland habitat was essential for the hawk. Bare ground and pasture has been shown to be very important for hunting by ferruginous hawks. In another study, Wakeley (1978) found hawks in Idaho to be hunting in bare ground and pasture significantly more than expected, and less than expected in grass-shrub, grain, old field, juniper, and rush-grass habitat. This suggests that the preference for non-cultivated areas may be strongly linked to prey. Although cultivation appears to be detrimental to the hawks, some forms of crop agriculture may not exclude these species. Using radio-telemetry, Leary et al. (1998) found that ferruginous hawks foraged in alfalfa fields (irrigated agricultural land) in a study area in Washington. They speculated that specific agricultural crops, such as alfalfa, may provide habitat for ferruginous hawk prey.

Ferruginous hawks are highly stenophagous (depending on few prey species). In Alberta, ground squirrels (Spermophilus spp.) make up the majority of the prey items (Bechard and Schmutz 1995). Populations of raptors tend to be limited by prey availability (Newton 1979). Hence, it would be hypothesized that a decline in a major prey item would be shadowed by a decline in the raptor dependent upon that prey. Consistent with this theory, ferruginous hawks were recorded in high numbers during years with high numbers of ground squirrels, and in low numbers during years with few ground squirrels (Figure 3). Other surveys conducted in southeastern Alberta also showed a strong correlation between ferruginous hawk and ground squirrel abundance (i.e. Schmutz and Hungle 1989) and documented an increase in breeding density and nesting success of ferruginous hawks in relation to an increase in ground squirrel abundance. Other populations of ferruginous hawks in North America have shown similar trends associated with prey densities. Howard and Wolfe (1976) noted a decrease in ferruginous hawk reproductive success in Utah and Idaho, which shadowed a decrease in prey densities (black-tailed jack rabbits, which was the major prey item in that region). In west-central Utah, Woffinden and Murphy (1977) documented a decline in ferruginous hawk nests during a decline in jack rabbit populations. Using more detailed correlation analysis, researchers suggested that jack rabbits, the dominant prey species for ferruginous hawks in the Great Basin study area, represented an important limiting factor for hawk reproduction (Smith et al. 1981). The Great Basin population of ferruginous hawks did not recover from the population low, and it has been speculated that poor reproductive success by the hawks, in combination with changes in the vegetation community (which essentially hinders large populations of rabbits), has contributed to the near extirpation of the hawk in this region (Woffinden and Murphy 1989). The apparent inability of the ferruginous hawk to recover from a prey crash is important for managers to consider, as management of prey populations is critical for long-term survival of this hawk in Alberta.

Although a relationship between ground squirrel abundance and ferruginous hawk numbers appears to exist in Alberta, survey methods used for ground squirrels in Alberta are biased and provide poor estimates of ground squirrel numbers, resulting in potentially inaccurate measures of abundance. Ground squirrel surveys in Alberta (for both ferruginous hawk and burrowing owl surveys) rely on burrow counts to estimate ground squirrel abundance. Van Horne et. al. (1997a) evaluated the effectiveness of burrow counts in indexing densities of a similar ground squirrel species (Spermophilus townsendii), and found that burrow counts provide a poor estimate of ground squirrel density when compared to actual numbers of squirrels recorded from livetrapping. In addition, they found trained observers to be inconsistent in assigning active-inactive 
status to burrow entrances. Similarly, in southern Alberta it was found that the noise and variable speeds of all terrain vehicles, surveyor inconsistencies in assigning active-inactive status of burrows, variability in timing of surveys, and biases in selecting sites to survey for ground squirrels, all contributed to inaccuracies in measures of ground squirrel abundance (Ursula Banasch pers. comm.). In order to better track the relationship between ground squirrel abundance and ferruginous hawk numbers, a better method for surveying ground squirrels is required. Live trapping, powder-tracking, and infrared thermal imaging are methods that have all successfully measured ground squirrel abundance (Hubbs et. al. 2000, Van Horne 1997b) and should be considered in future Alberta surveys.

Data from burrowing owl surveys suggest that ground squirrel numbers vary markedly between regions in southern Alberta. Two different regions within the larger ferruginous hawk study area were surveyed for ground squirrels as part of the burrowing owl surveys in 1997, 1998, and 2000; showing differences in ground squirrel numbers (Table 4). Regional variation in nest abundance of ferruginous hawks in Alberta in 2000 may have been directly related to regional variation in ground squirrel abundance. For example, in the Milk River/Lethbridge region, large numbers of ground squirrels were noted during 2000 through both personal observations and landowner information. An increase in the number of ferruginous hawk nests was also observed in this region, when compared to 1992 numbers (Figure 4). The relationship between regional increases in both ground squirrels and ferruginous hawks is consistent with the prey abundance theory, and is a reminder of how important prey populations may be to the ferruginous hawk's nest success. Squirrel abundance is also related to percent cultivation of their habitat (Schmutz 1989), meaning that although we relate cultivation to reduced hawk numbers, the real driver may be the lack of ground squirrels on that land.

There are several other factors that could contribute to the observed decline of the ferruginous hawk in Alberta. Changes in global climate could result in more and/or longer drought periods and other ecological changes that cannot be tested with the present data set. It is also unclear how agricultural practices on the wintering grounds may be affecting the Alberta populations of ferruginous hawks. As a migratory species, the majority of ferruginous hawks that breed in Alberta are known to spend the winter months in Texas (Schmutz and Fyfe 1987). With little known about these wintering grounds, it is difficult to assess the effect that land-use practices in those regions may be having on the Alberta population. Finally, no analysis was carried out on nest site availability for ferruginous hawks in Alberta. The availability of nest sites (such as trees and nesting platforms) has been shown to be an important factor for ferruginous hawks (Schmutz 1984 ) and a decline in such sites could have a major impact on local populations. 


\subsection{MANAGEMENT IMPLICATIONS AND FUTURE DIRECTIONS}

The dramatic decline in the population of ferruginous hawks in southeastern Alberta should be of concern to wildlife managers. Data suggest that the decline is associated with a decline in ground squirrel populations; therefore it is critical that both ferruginous hawks and ground squirrels be protected and monitored in the future. There is reason for concern, because very little is known about ground squirrels in Alberta and it is difficult to determine if whether a decline in their numbers is natural or human-induced. Furthermore, although data suggest that the ferruginous hawk decline may be associated with ground squirrels, there exist other threats that may be acting on the species and these require investigation.

In order to track the future of both ferruginous hawks and their prey, several management initiatives should be carried out:

1) Ferruginous hawk surveys should continue, and be increased in frequency to annual surveys, rather than the traditional 5-year surveys.

Although the ferruginous hawk 5-year surveys have the potential to continue to track gross changes in the ferruginous hawk population of southeastern Alberta, annual fluctuations with possible 'good' and 'bad' years may result in misleading trends in the dataset. For example, if a storm event destroys several ferruginous hawk nests in a survey year, a low number of nest sites would be detected by surveyors, suggesting an artificially low number of ferruginous hawks. By surveying every year, this annual variability can be better understood and controlled for in future analysis. If managers are serious about gaining a better understanding of ferruginous hawk populations over time, it would be advantageous to survey the hawks annually, as well as ground squirrels. Given that resources and staff may be limited within the government, this could be best accomplished by a shared project between a university or similar research institution and the government of Alberta. This sharing of research has been successfully demonstrated in the past for ferruginous hawks, as seen by Joe Schmutz's work in the Hanna study area.

2) A consistent and regular system of surveying ground squirrels must be established for the prairies of Alberta. Annual surveys should be established for Richardson ground squirrels.

At present, ground squirrel surveys are conducted largely as side-projects during larger surveys such as the ferruginous hawk or burrowing owl surveys. Ground squirrel populations appear to be driving ferruginous hawk populations and populations of other grassland species, such as burrowing owls (Shyry pers. comm.). Although ground squirrel importance to the prairie ecosystem is not fully understood, the majority of studies conducted on the prairies suggest that ground squirrel survival is critical to the health of this ecosystem. For this reason, gaining a better understanding of ground squirrel population dynamics and functionality in the prairies should be a priority for wildlife managers. Burrow counts are poor estimators of ground squirrel abundance (Van 
Horne et. al. 1997a) and should no longer be used in Alberta surveys. Rather, live trapping, powder-tracking, and infrared thermal imaging should be considered as methods for determining ground squirrel abundance, as they have proven successful in other parts of North America (Hubbs et. al. 2000, Van Horne 1997b).

\section{3) Landholder contact should remain a priority.}

From a land-use perspective, it is critical that the public and industry remain involved in wildlife management pertaining to species that require pasture and native prairie, such as ferruginous hawks. Where feasible, ranching should be encouraged in the grasslands of Alberta as an alternative to cultivation. Pamphlets that outline the value of ground squirrels to the prairie ecosystem could be one of many tools to help with this education process. Land stewardship programs and land-owner education has proven successful in these areas and should continue into the future. Although oil and gas activity appear to have no effect on ferruginous hawk abundance in this survey, this activity should be monitored closely. Actual human activity (such as drilling and extensive traffic) in the area of breeding hawks should be minimized or only conducted in winter months, where possible. Although guidelines have instituted no-activity zones around ferruginous hawk nests (Scobie and Faminow 2000), little information exists on the effect of drilling in hawk nesting areas in Alberta. This must be better understood as the footprint of oil and gas increases throughout the ferruginous hawk's nesting range.

\section{4) Research should focus on specific areas of concern to the ferruginous hawk in Alberta.}

The prairie landscape is ever-changing, with both natural and human events having an impact on vegetation and wildlife. It is important to determine how these changes may be affecting the ferruginous hawk. Questions that should be addressed in future research include: 1) Is ferruginous hawk productivity affected by oil and gas activity? 2) Have the number of ferruginous hawk nesting poles declined in the past decade, and has this change in nesting platforms affected the ferruginous hawk? 3) Is climate change likely to change the fortunes of the ferruginous hawk in Alberta? 


\subsection{LITERATURE CITED}

Province of Alberta. 1999. Wildlife Regulation (Alberta Regulation 143/97). Queen's Printer. 273 pp.

Bechard, M.J. and J.K. Schmutz. 1995. Ferruginous hawk (Buteo regalis). In: The Birds of North America, No. 172. (A. Poole, and G.Gill eds.) Academy of Natural Sciences, Philadelphia, PA. 20 pp.

COSEWIC. 2001. Species at risk: Ferruginous hawk.

http://www.speciesatrisk.gc.ca/Species/English/SearchDetail.cfm?SpeciesID=47 [Accessed May, 2001]

Gilmer, D.S. and R.E. Stewart. 1983. Ferruginous hawk populations and habitat use in North Dakota. Journal of Wildlife Management 47(1):146-157.

Howard, R.P. and M.L. Wolfe. 1976. Range improvement practices and ferruginous hawks. Journal of Range Management 29(1):33-37.

Hubbs, A.H., T. Karels, and R. Boonstra. 2000. Indices of population size for burrowing mammals. Journal of Wildlife Management 64(1):296-301.

Leary, A.W., R. Mazaika, and M.J. Bechard. 1998. Factors affecting the size of ferruginous hawk home ranges. Wilson Bulletin 110(2):198-205.

Newton, I. 1979. Population ecology of raptors. Buteo books, Vermillion, SD. 399 pp.

Schmutz, J.K. 1982. An estimate of ferruginous hawks in Alberta and the relationship between their density and land use. Unpubl. Rept. For the Alberta Environmental Research Trust and the Fish and Wildlife Division of Alberta Energy and Natural Resources. Edmonton, AB. 28 pp.

Schmutz, J.K. 1984. Ferruginous and Swainson's hawk abundance and distribution in relation to land use in southeastern Alberta. Journal of Wildlife Management 48(4):1180-1187.

Schmutz, J.K. 1987a. An estimate of population size and probable causes of population stability in ferruginous hawks in southeastern Alberta. Unpubl. Rept. For Alberta Division of Fish and Wildlife. Edmonton, AB. 41 pp.

Schmutz, J.K. 1987b. The effect of agriculture on ferruginous and Swainson's hawks. Journal of Range Management 40(5):438-440.

Schmutz, J.K. 1989. Hawk occupancy of disturbed grasslands in relation to models of habitat selection. The Condor 91:362-371. 
Schmutz, J.K. 1993. Population trends of ferruginous hawks in Alberta, including a synthesis for prairie Canada. Unpubl. Rept. For the Committee on the Recovery of Nationally Endangered Wildlife in Canada (RENEW), Ottawa, On. 21. pp.

Schmutz, J.K. 1999. Status of the ferruginous hawk (Buteo regalis) in Alberta. Alberta Environmental Protection, Fisheries and Wildlife Management Division, and Alberta Conservation Association, Wildlife Status Report No. 18, Edmonton, AB. 18 pp.

Schmutz, J.K. and R.W. Fyfe. 1987. Migration and mortality of Alberta ferruginous hawks. Condor 89:169-174.

Schmutz, J.K. and D.J. Hungle. 1989. Populations of ferruginous hawks increase in synchrony with ground squirrels. Canadian Journal of Zoology 67:2596-2601.

Scobie, D. and C. Faminow. 2000. Development of standardized guidelines for petroleum industry activities that affect COSEWIC Prairie and Northern Region vertebrate species at risk. Report for Environment Canada, Prairie and Northern Region, Edmonton, Alberta. $21 \mathrm{pp}$.

Smith, D.G., J.R. Murphy, and N.D. Woffinden. 1981. Relationships between jackrabbit abundance and ferruginous hawk reproduction. Condor 83:52-56.

Strong, W.L. and K.R. Leggat. 1992. Ecoregions of Alberta. Alberta Forestry, Lands and Wildlife. Publication Number T/245. Edmonton, AB. 59 pp. Plus map.

Taylor, B. and J. Iwaasa. 2000a. 2000 ferruginous hawk survey results; preliminary report. Unpubl. Rept. For Alberta Environment, Natural Resources Service. 48 pp.

Taylor, B. and J. Iwaasa. 2000b. 2000 ferruginous hawk survey results; foothills fescue natural subregion, preliminary report. Unpubl. Rept. For Alberta Environment, Natural Resources Service. 12 pp.

Van Horne, B., R.L. Schooley, S.T. Knick, G.S. Olson, and K.P. Burnham. 1997a. Use of burrow entrances to indicate densities of Townsend's ground squirrels. Journal of Wildlife Management 61(1):92-101.

Van Horne, B., G.S. Olson, R.L. Schooley, J.G. Corn, and K.P. Burnham. 1997b. Effects of drought and prolonged winter on Townsend's ground squirrel demography in shrubsteppe habitats. Ecological Monographs 67(3):295-315.

Wakeley, J.S. 1978 Factors affecting the use of hunting sites by ferruginous hawks. Condor 80:316-326.

White, C.M. and T.L. Thurow. 1985. Reproduction of ferruginous hawks exposed to controlled disturbance. Condor 87:14-22. 
Woffinden, N.D. and J.R. Murphy. 1977. Population dynamics of the ferruginous hawk during a prey decline. The Great Basin Naturalist 37(4):411-425.

Woffinden, N.D. and J.R. Murphy. 1989. Decline of a ferruginous hawk population: a 20-year summary. Journal of Wildlife Management 53(4):1127-1132.

Zelenak, J.R. and J.J. Rotella. 1997. Nest success and productivity of ferruginous hawks in northern Montana. Canadian Journal of Zoology 75:1035-1041. 


\section{List of Titles in This Series}

(as of March 2002)

No. 1 Alberta species at risk program and projects 2000-2001, by Alberta Sustainable Resource Development, Fish and Wildlife Division. (2001)

No. 2 Survey of the peregrine falcon (Falco peregrinus anatum) in Alberta, by R. Corrigan. (2001)

No. 3 Distribution and relative abundance of the shortjaw cisco (Coregonus zenithicus) in Alberta, by M. Steinhilber and L. Rhude. (2001)

No. 4 Survey of the bats of central and northwestern Alberta, by M.J. Vonhof and D. Hobson. (2001)

No. 52000 survey of the Trumpeter Swan (Cygnus buccinator) in Alberta, by M.L. James and A. James. (2001)

No. 6 2000/2001 Brassy Minnow inventory at Musreau Lake and outlet, by T. Ripley. (2001)

No. 7 Colonial nesting waterbird survey in the Northwest Boreal Region - 2000, by M. Hanneman and M. Heckbert. (2001)

No. 8 Burrowing owl trend block survey and monitoring - Brooks and Hanna areas, by D. Scobie and R. Russell. (2000)

No. 9 Survey of the Lake Sturgeon (Acipenser fulvescens) fishery on the South Saskatchewan River, Alberta (June-September, 2000), by L.A. Winkel. (2000)

No. 10 An evaluation of grizzly bear-human conflict in the Northwest Boreal Region of Alberta (19912000 ) and potential mitigation, by T. Augustyn. (2001)

No. 11 Harlequin duck monitoring in the Northern East Slopes of Alberta: 1998-2000 preliminary results, by J. Kneteman and A. Hubbs. (2000)

No. 12 Distribution of selected small mammals in Alberta, by L. Engley and M. Norton. (2001)

No. 13 Northern leopard frog reintroduction. Raven River - Year 2 (2000), by K. Kendell. (2001)

No. 14 Cumulative effects of watershed disturbances on fish communities in the Kakwa and Simonette watersheds. The Northern Watershed Project. Study 3 Progress report, by T. Thera and A. Wildeman. (2001)

No. 15 Harlequin duck research in Kananaskis Country in 2000, by C.M. Smith. (2001)

No. 16 Proposed monitoring plan for harlequin ducks in the Bow Region of Alberta, by C.M. Smith. (2001)

No. 17 Distribution and relative abundance of small mammals of the western plains of Alberta as determined from great horned owl pellets, by D. Schowalter. (2001)

No. 18 Western blue flag (Iris missouriensis) in Alberta: a census of naturally occurring populations for 2000, by R. Ernst. (2000)

No. 19 Assessing chick survival of sage grouse in Canada, by C.L. Aldridge. (2000)

No. 20 Harlequin duck surveys of the Oldman River Basin in 2000, by D. Paton. (2000) 
No. 21 Proposed protocols for inventories of rare plants of the Grassland Natural Region, by C. Wallis. (2001)

No. 22 Utilization of airphoto interpretation to locate prairie rattlesnake (Crotalus viridis viridis) hibernacula in the South Saskatchewan River valley, by J. Nicholson and S. Rose. (2001)

No. 23 2000/2001 Progress report on caribou research in west central Alberta, by T. Szkorupa. (2001)

No. 24 Census of swift fox (Vulpes velox) in Canada and Northern Montana: 2000-2001, by A. Moehrenschlager and C. Moehrenschlager. (2001)

No. 25 Population estimate and habitat associations of the long-billed curlew in Alberta, by E.J. Saunders. (2001)

No. 26 Aerial reconnaissance for piping plover habitat in east-central Alberta, May 2001, by D.R.C. Prescott. (2001)

No. 27 The 2001 international piping plover census in Alberta, by D.R.C. Prescott. (2001)

No. 28 Prairie rattlesnake (Crotalus viridis viridis) monitoring in Alberta - preliminary investigations (2000), by S.L. Rose (2001)

No. 29 A survey of short-horned lizard (Phrynosoma hernandesi hernandesi) populations in Alberta, by J. James (2001)

No. 30 Red-sided garter snake (Thamnophis sirtalis parietalis) education and relocation project - final report, by L. Takats (2002)

No. 31 Alberta furbearer harvest data analysis, by K.G. Poole and G. Mowat (2001)

No. 32 Measuring wolverine distribution and abundance in Alberta, by G. Mowat (2001)

No. 33 Woodland caribou (Rangifer tarandus caribou) habitat classification in northeastern Alberta using remote sensing, by G.A. Sanchez-Azofeifa and R. Bechtel (2001)

No. 34 Peregrine falcon surveys and monitoring in the Parkland Region of Alberta, 2001, by R. Corrigan (2002)

No. 35 Protocol for monitoring long-toed salamander (Ambystoma macrodactylum) populations in Alberta, by T. Pretzlaw, M. Huynh, L. Takats and L. Wilkinson (2002)

No. 36 Long-toed salamander (Ambystoma macrodactylum) monitoring study in Alberta: summary report 1998-2001, by M. Huynh, L. Takats and L. Wilkinson (2002)

No. 37 Mountain plover habitat and population surveys in Alberta, 2001, by C. Wershler and C. Wallis (2002)

No. 38 A census and recommendations for management for western blue flag (Iris missouriensis) in Alberta, by R. Ernst (2002)

No. 39 Columbian mountain amphibian surveys, 2001, by D. Paton (2002)

No. 40 Management and recovery strategies for the Lethbridge population of the prairie rattlesnake, by R. Ernst (2002) 
No. 41 Western (Aechmophorus occidentalis) and eared (Podiceps nigricollis) grebes of central Alberta: inventory, survey techniques and management concerns, by S. Hanus, H. Wollis and L. Wilkinson (2002)

No. 42 Northern leopard frog reintroduction - year 3 (2001), by K. Kendell (2002)

No. 43 Survey protocol for the northern leopard frog, by K. Kendell (2002)

No. 44 Alberta inventory for the northern leopard frog (2000-2001), by K. Kendell (2002)

No. 45 Fish species at risk in the Milk and St. Mary drainages, by RL\&L Environmental Services Ltd. (2002)

No. 46 Survey of the loggerhead shrike in the southern aspen parkland region, 2000-2001, by H. Kiliaan and D.R.C. Prescott (2002)

No. 47 Survey of native grassland butterflies in the Peace parkland region of northwestern Alberta - 2001, by M. Hervieux (2002)

No. 48 Caribou range recovery in Alberta: 2001/02 pilot year, by T. Szkorupa (2002)

No. 49 Peace parkland native grassland stewardship program 2001/02, by A. Baker (2002)

No. 50 Carnivores and corridors in the Crowsnest Pass, by C. Chetkiewicz (2002)

No. 512001 Burrowing owl trend block survey and monitoring, Brooks and Hanna areas, by D. Scobie (2002)

No. 52 An evaluation of the ferruginous hawk population in Alberta based on recent trend data, by D.P. Stepnisky, G.L. Erickson, J. Iwaasa and B. Taylor (2002) 



National Library of Canada

National Library of Canada
Bibliotheque nationale du Canada 